J-DEPACE, Volume 2, Nomor 1, Juni 2019, Hal. 66-74

Tersedia online di :http://jurnal.lpmiunvic.ac.id/index.php/jpkm

\title{
IDENTIFIKASI GEJALA SERANGAN HAMA DAN PENYAKIT UTAMA \\ TANAMAN KAKAO (Theobroma cacao L) SERTA UPAYA PENGENDALIANNYA
}

\author{
Cornelia. M.A. Wattimena \\ Program Studi Kehutanan, Universitas Pattimura Ambon \\ email: wattimenacma@gmail.com
}

\begin{abstract}
ABSTRAK
Tanaman kakao, merupakan salah satu komoditas perkebunan yang memiliki peluang usaha dan nilai ekonomi yang tinggi. Dalam pengusahaan tanaman kakao terdapat kendala yang dapat menurunkan produksi dan mutu kakao, yaitu serangan hama dan penyakit. Pengabdian masyarakat yang dilakukan di Desa Kawa berupa penyuluhan tentang identifikasi gejala serangan hama dan penyakit utama tanaman kakao (Theobroma cacao, L) dan upaya pengendaliannya, bertujuan untuk meningkatkan pengetahuan masyarakat tentang pengenalan jenis hama dan penyakit dan gejalanya sehingga usaha pengendalian dapat berhasil dengan baik. Hasil akhir dari kegiatan pengabdian ini, masyarakat desa kawa sudah dapat mengetahui dengan jelas gejala kerusakan tanaman kakao yang disebabkan akibat serangan serangga hama dan serangan penyakit serta upaya pengendaliannya.
\end{abstract}

Kata kunci : serangan, hama, penyakit.

\section{ABSTRACT}

Cocoa plants are one of the plantation commodities that have great business opportunities and economic value. In the cultivation of cocoa, some obstacles can reduce the production and quality of cocoa, namely attacks of pests and diseases. Community service carried out in Kawa village in the form of counseling on the identification of symptoms of major pest and disease attacks on cocoa (Theobroma cacao, L) and its control efforts, aims to increase community knowledge about the introduction of pests and diseases and symptoms so that control efforts can work well. The final result of this service activity, the people of Kawa village, have been able to know the symptoms of damage to cocoa plants caused by insect attacks of pests and disease attacks and efforts to control them.

Keywords: attacks, pests, diseases 


\section{PENDAHULUAN}

Irian Jaya (sekarang menjadi Papua dan Papua Barat), Kalimantan Timur, Sulawesi Tengah, Maluku dan Sulawesi Tenggara memiliki lahan potensial yang cukup besar untuk pengembangan kakao. Tanaman kakao, merupakan salah satu komoditas perkebunan yang memiliki peluang usaha dan nilai ekonomi yang tinggi. Hal ini dikarenakan kakao merupakan bahan baku coklat yang bisa dipanen tiap hari, berbuah sepanjang tahun tanpa mengenal musim. Dalam budidaya kakao tak perlu waktu lama dalam memanen buah coklat dari pohonnya, proses pemanenannya pun bisa dilakukan tiap hari jika sudah ada kakao yang tua atau siap dipanen.

Usaha pengembangan tanaman kakao secara luas sering mengalami hambatan, salah satunya adalah serangan hama dan penyakit. Serangan hama dan penyakit merupakan salah satu faktor utama rendahnya produksi biji kakao. Selain itu, serangan hama dan penyakit juga berpengaruh besar terhadap kualitas biji kakao yang dihasilkan.

Kakao termasuk tanaman perkebunan yang biasanya dibudidayakan di areal yang luas. Dengan demikian pembudidayaan tanaman kakao dapat menciptakan keadaan iklim mikro yang relatif stabil, baik dari sisi pencahayaan matahari, kelembaban dan sebagainya. Akibat negatif dari kondisi iklim yang stabil ini adalah berkembangnya hama dan penyakit dengan lebih baik, karena makanannya selalu tersedia. Oleh karena itu pengenalan jenis hama dan penyakit utama pada kakao di Maluku dan gejalanya sangat diperlukan agar dalam usaha pengendaliannya dapat berhasil dengan baik.

\section{MASALAH}

Masyarakat Desa Kawa yang terletak di Kabupaten Seram bagian Barat Provinsi Maluku merupakan salah satu desa yang sebagian besar masyarakatnya, bermata pencaharian sebagai petani subsisten. Jenis tanaman yang mereka usahakan beragam, baik tanaman hortikultura, tanaman pangan, tanaman kehutanan maupun tanaman umur panjang, baik itu tanaman buah-buahan maupun tanaman perkebunan. Salah satu jenis tanaman perkebunan yang diusahakan adalah tanaman kakao. Namun, produktivitas tanaman kakao selalu mengalami penurunan dan yang menjadi kendala utama adalah tingkat serangan hama dan penyakit.

Berdasarkan permasalahan tersebut, maka dilakukan pengabdian kepada masyarakat berupa penyuluhan tentang identifikasi serangan hama dan penyakit utama tanaman kakao 
(Theobroma cacao L) dan upaya pengendaliannya. Kegiatan ini diharapkan dapat menambah wawasan dan pengetahuan masyarakat sebagai upaya preventif dalam mengembangkan tanaman tersebut.

\section{METODE}

Metode yang digunakan pada kegiatan ini adalah memberikan pengetahuan kepada masyarakat berupa penyuluhan tentang bagaimana masyarakat desa Kawa dapat mengetahui lebih awal gejala serangan hama dan penyakit utama tanaman kakao dan upaya pengendaliannya.
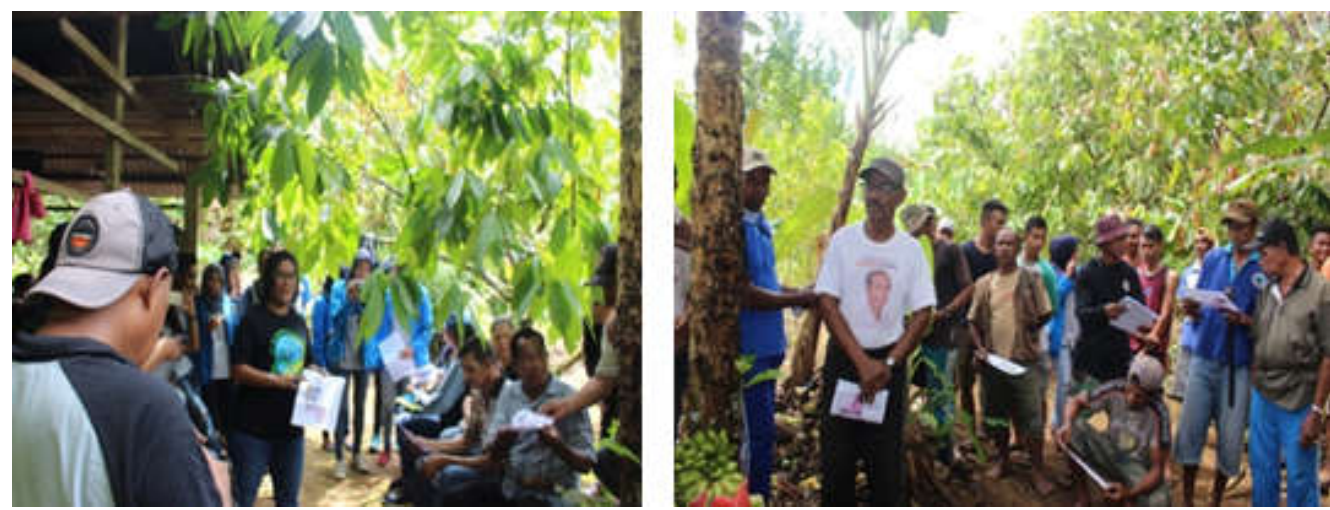

Gambar 1. Kegiatan Penyuluhan di Lahan Masyarakat

\section{HASIL DAN PEMBAHASAN}

Jenis organisme penganggu tanaman kakao (Theobroma cacao L) di Indonesia jumlahnya sangat banyak. Menurut Entwistle (1972) dalam Puslitkoka (2004), terdapat lebih dari 130 species serangga yang berasosiasi dengan tanaman kakao. Di Maluku hama utama yang biasanya menyerang tanaman kakao yaitu Penggerek Buah Kakao (PBK), penghisap buah, penggerek batang dan kutu putih, sedangkan penyakit utama yang biasanya menyerang tanaman kakao yaitu penyakit busuk buah dan kanker batang.

\subsection{Hama Utama Yang Menyerang Tanaman Kakao}

a. Penggerek Buah Kakao / PBK (Conopomorpha cramerella Snell.) atau Cacao Moth

\section{1) Gejala Serangan dan Kerusakan}

a) Umumnya menunjukkan gejala belang kuning-hijau 
b) Biji saling lengket

c) Menghasilkan biji berukuran kecil dan bermutu rendah
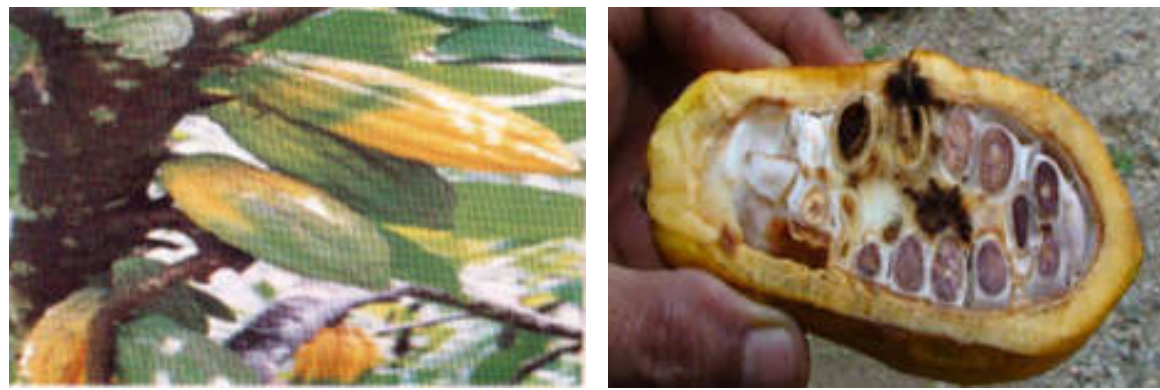

Gambar 2. Buah yang Terserang

2) Upaya Pengendalian :

Wajib (Secara fisik/mekanik)

a) Pemangkasan pemendekan tajuk $(<4 \mathrm{M})$ memudahkan panen, pengendalian hama dan penyakit

b) Pemupukan, agar, tanaman sehat, produksi tinggi, empat tepat : jenis, waktu, dosis dan cara

c) Panen sering dan Sanitasi, untuk membunuh ulat PBK dengan membenamkan kulit buah, gulma

d) Pemilihan pohon pelindung, misalnya : jati, suren, mahoni, kopi, kapok, kina, , kayu manis, rambutan (harus dihindari karena tumbuhan inang dari PBK)

\section{Tambahan :}

a) Penyarungan buah, bertujuan mencegah ngengat PBK bertelur. Hal ini bisa menyelamat buah dari PBK sampai $80 \%$.

b) Semut hitam/semut merah pengendalian PBK dan Helopelti. Populasi semut yang berlimpah dapat menekan serangan PBK, pemasangan sarang dari daun kelapa atau daun kakao. Areal yang ada semut sebaiknya tidak disemprot insektisida secara intensif (secara hayati)

Pengendalian Secara Hayati yaitu : penggunaan (daun sirsak, daun cengkeh, mimba, daun pepaya yang telah diekstraksi terlebih dahulu)

Pengendalian Secara kimiawi, seperti merek : $500 \mathrm{ml}$ Capture, $250 \mathrm{ml}$ Chlormite dan 1 botol Alika atau $250 \mathrm{ml}$ Chlormite dan Ventra 


\section{b. Penghisap Buah (Helopeltis spp)}

\section{1) Gejala Serangan}

a) Menyerang buah muda (pentil) dan pucuk kakao (die back)

b) Buah berwarna hitam atau bercak hitam
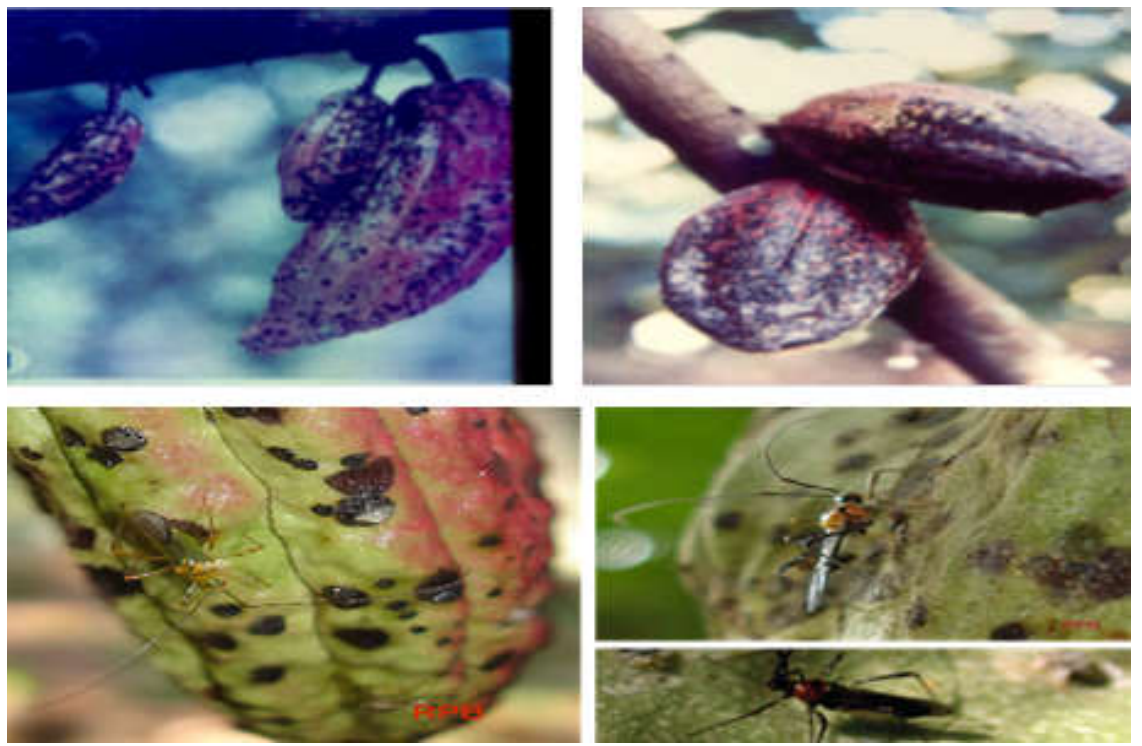

Gambar 3.Gejala Serangan Helopeltis spp

\section{2) Upaya Pengendalian}

a) Secara hayati dengan semut hitan

b) Secara kimiawi tidak dapat digabung dengan pengendalian hayati

\section{c. Penggerek Batang (Zeuzera coffeae Nietn)}

\section{1) Gejala Serangan}
a) Biasanya menyerang tanaman muda
b) Terdapat lubang gerek pada batang/cabang
c) Pada permukaan lubang terdapat kotoran ulat campur bekas gerekan
d) Tanaman diatas lubang gerek mati
e) Tanaman inangnya : jati, suren, mahoni, kopi, kapok.

\section{2) Upaya Pengendalian}

\section{a) Secara Mekanis}

Memotong batang atau cabang yang terserang pada jarak $10 \mathrm{~cm}$ kearah pangkal dari lubang gerek kemudian larva atau kepompong harus segera di bunuh 
b) Secara Hayati

Penyemprotan dengan jamur B.bassiana
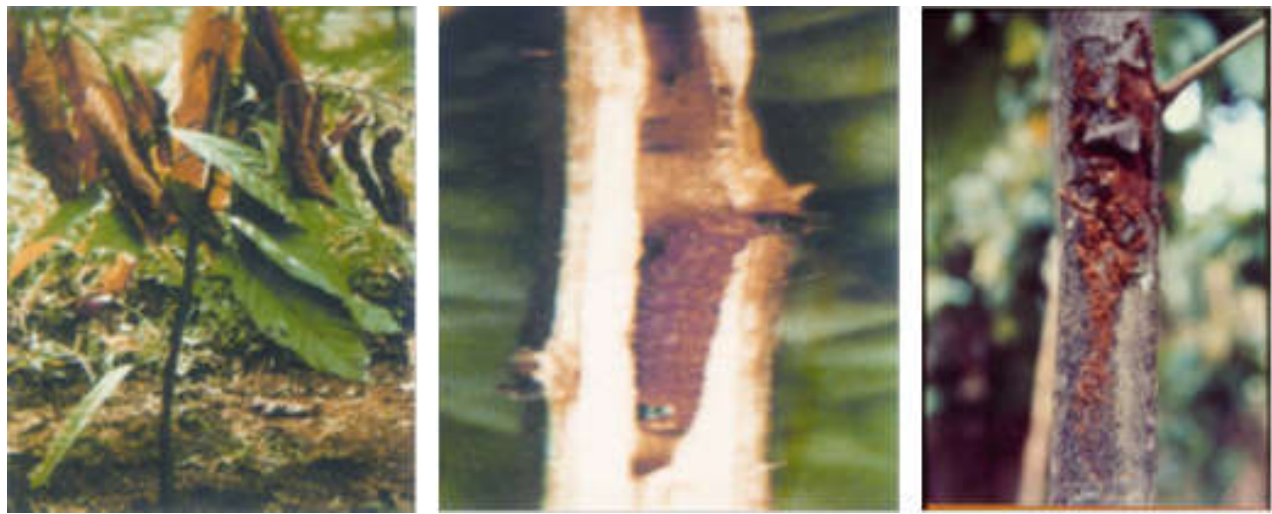

Gambar 4. Kakao Yang Tersebang Penggerek Batang

\section{d. Kutu Putih}

Kutu putih belum pernah dilaporkan secara eksplosif menimbulkan kerusakan yang serius pada tanaman kakao, namun keberadaannya paling sering ditemukan. Bahkan keberadaannya sangat diharapkan karena bersimbiosis dengan semut hitam dan semut rangrang (semut merah).

Kutu putih dapat menjadi alternatif pengendalian hama lainnya seperti penggerek buah kakao dan penghisap buah kakao, karena jika menempel pada buah, kutu putih justru dapat mengundang semut hitam yang merupakan predator beberapa hama. Semut memerlukan cairan manis yang dikeluarkan kutu putih sebagai sumber makanannya sedangkan kutu putih memerlukan semut untuk penyebaran dan perlindungan kakao
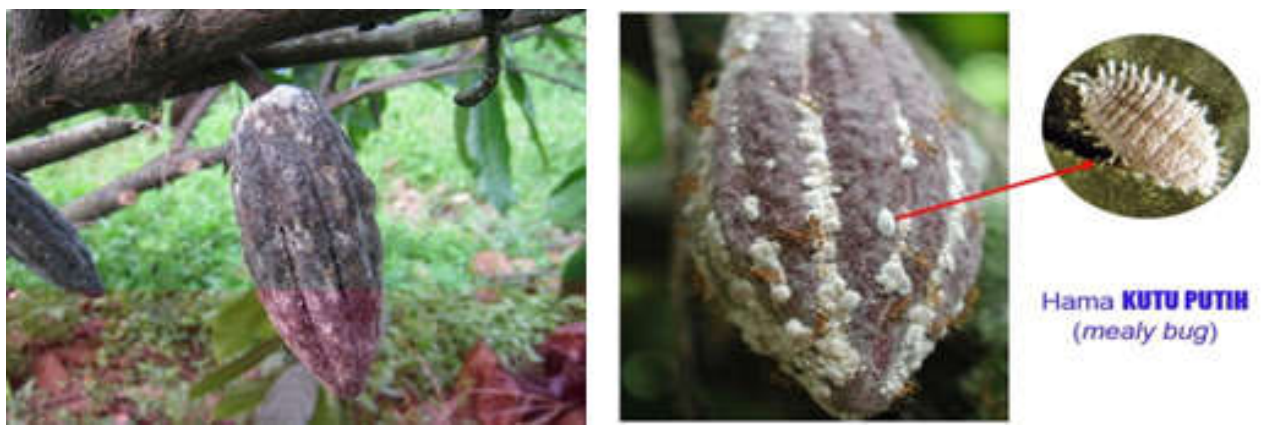

Gambar 5. Hama Kutu Putih 


\subsection{Penyakit Utama Yang Menyerang Tanaman Kakao}

a. Busuk Buah (Phytophthora palmivora Butl)

1) Gejala Awal

Bercak coklat pada permukaan buah/batang, umumnya pada ujung atau pangkal buah yang bila diraba akan terasa lembah atau basah

2) Gejala Lanjutan

Bercak membesar berwarna coklat yang amat jelas, membedakan dengan warna yang masih sehat disekeliling bercak tersebut, warna buah akhirnya berubah hitam

3) Penyebaran

Jamur P. palmivora dapat melalui percikan air hujan, hubungan langsung antara buah sakit dan sehat, melalui perantara binatang (tikus, tupai, bekicot, semut)
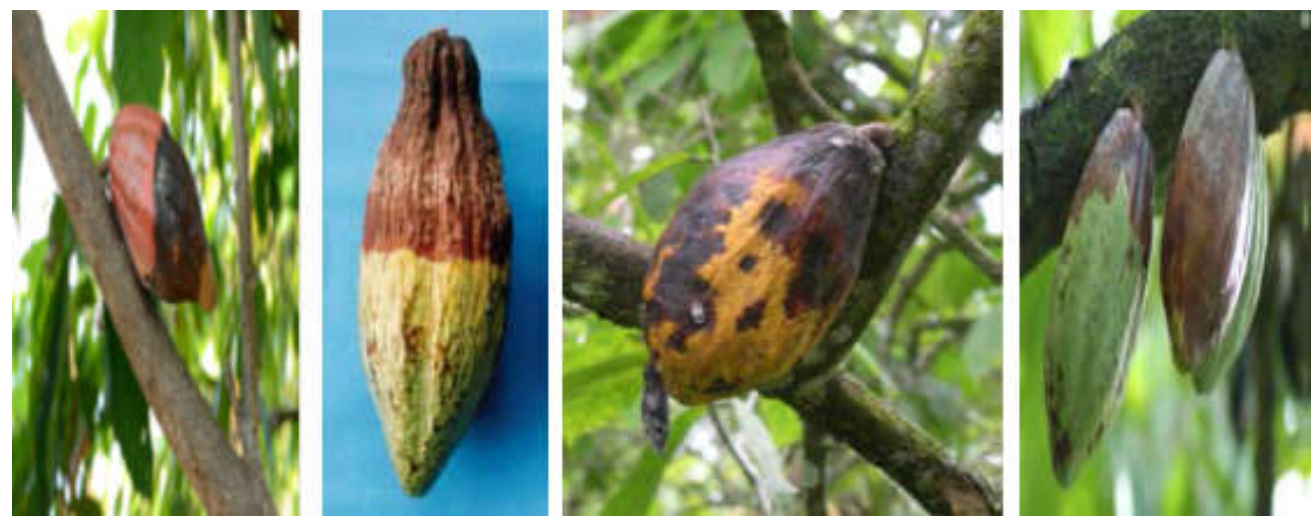

Gambar 6. Penyakit Busuk Buah

4) Upaya Pengendalian

a) Sanitasi kebun

b) Pengaturan pohon pelindung

c) Pemangkasan

\section{b. Kanker Batang}

1) Gejala

a) Kulit batang agak retak (pecah-pecah) dan berwarna lebih gelap atau kehitamhitaman

b) Sering terdapat cairan kemerahan yang kemudian terlihat seperti lapisan karat

c) Jika lapisan kulit luar dibersihkan maka tampak laipsan dibawahnya membusuk dan berwarna merah anggur. 

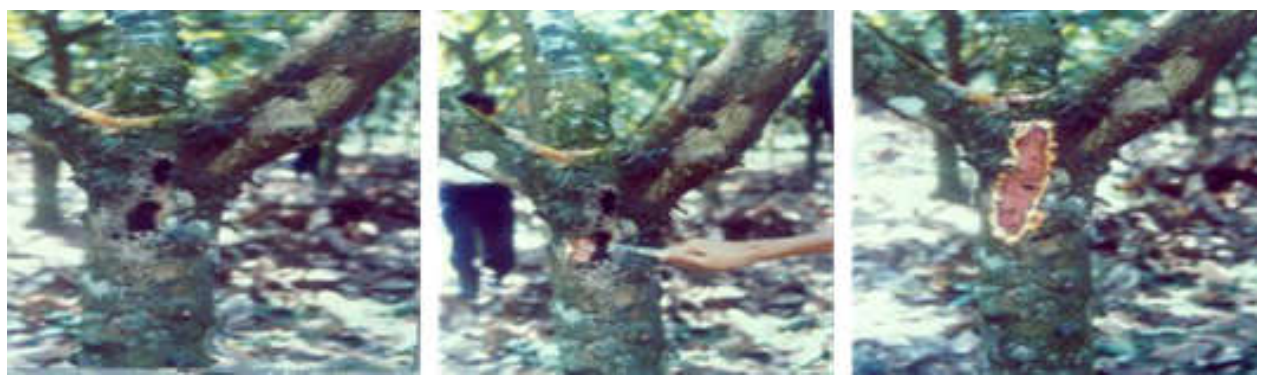

2) Pengendaliannya

\section{Secara Fisik/Mekanik}

a) Kulit batang yang membusuk dikupas sampai batas kulit yang sehat

b) Luka kupasan selanjutnya dioles dengan fungisida
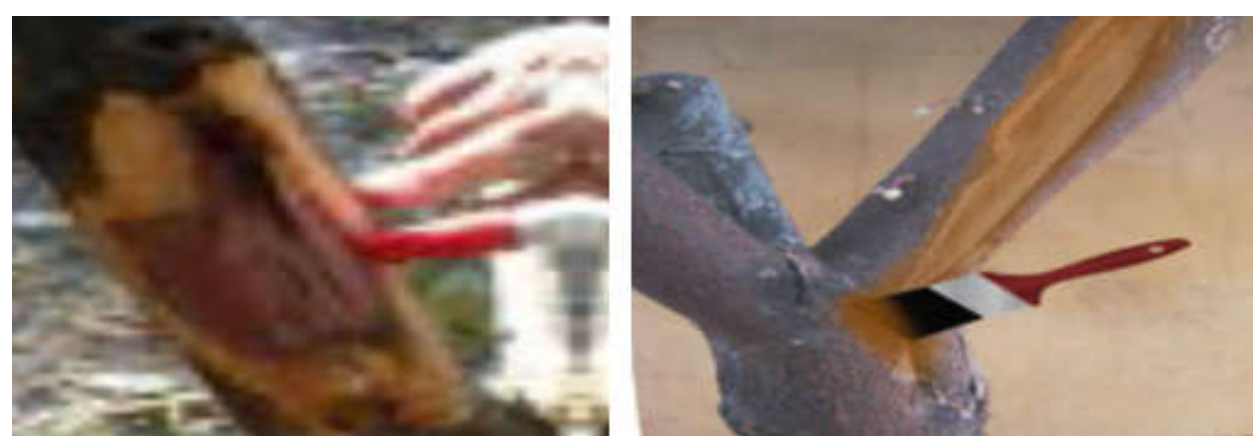

\section{Secara Hayati}

a) Pestisida Nabati

\section{KESIMPULAN}

Tanaman kakao, merupakan salah satu komoditas perkebunan yang memiliki peluang usaha dan nilai ekonomi yang tinggi. Oleh sebab tindakan preventif sebagai upaya pengendalian serangan hama dan penyakit utama harus dikenali secata teliti lebih awal sehingga dapat meningkatkan produktivitas tanaman kakao. 


\section{DAFTAR PUSTAKA}

Matitaputty A, Amanupunyo H.R.D, Rumahlewang W, 2014. Kerusakan Tanaman Kakao (Theobroma cacao L) Akibat Penyakit Penting di Kecamatan Taniwel Kabupaten Seram Bagian Barat.

Pesireron M, 2007. Pengendalian Hama Terpadu Tanaman Kakao di Maluku. Balai Pengkajian Teknologi Pertanian - Ambon

Pusat Penelitian Kopi dan Kakao Indonesia (Puslitkoka), 2004. Kiat Mengatasi Permasalahan Praktis. Panduan Lengkap Budidaya Kakao. Agromedia Pustaka 